\title{
Pengaruh Harmonic pada Peralatan Tegangan Satu Phasa di Ruangan Administrasi Bandara
}

\section{Harmonic Effect on Single Phase Voltage Equipment in Airport Administration Room}

\author{
Catra Indra Cahyadi ${ }^{*}$, I Gusti Agung Ayu Mas Oka², Yanti Daryanti ${ }^{3}$ \\ ${ }_{1,2,3}$ Polteknik Penerbangan Palembang \\ Jl. Adi Sucipto No.3012, Sukodadi, Kota Palembang, Sumatera Selatan \\ catraindracahyadi@gmail.com¹, igaayu1978@gmail.com², yantiaji1964@gmail.com³
}

\begin{abstract}
Abstrak - Beban non linier yang belum berbentuk gelombang sinusoidal telah terdistorsi oleh distorsi harmonisa arus. Beban non linier merupakan salah satu penyebab timbulnya distorsi yang dapat mengakibatkan kualitas daya listrik semakin buruk. Paper ini membahas hasil simulasi penggunaan filter tunggal yang disetel untuk mengurangi distorsi yang disebabkan oleh beban non linier akibat personal computer dan printer untuk pencetakan. Pengukuran menggunakan alat power quality analyzer fluke. Hasil pengukuran terhadap 4 merk PC yang berbeda menunjukan bahwa nilai beban non linier yang dihasilkan mengalami penurunan. Beban personal komputer merk A dari THDi sebesar 120,7\% menurun menjadi 110,8\%, merk B dari THDi sebesar 121,9\% menjadi 109,9\%, merk C dari THDi sebesar 150,1\% menurun menjadi 100,2 \%, merk D dari THDi sebesar 176,2\% menurun menjadi 104,1\%. Penurunan total harmonic distorsion arus setelah direduksi sebesar 0,8-1\%. Penggunaan filter berhasil menurunkan nilai THDi.
\end{abstract}

Kata Kunci: THD, distortion analyzer, power quality, harmonic.

\begin{abstract}
Abstrak - Non-linear loads that have not been in the form of sinusoidal waves have been distorted by current harmonic distortion. Non-linear loads, one of the causes of distortion can cause the quality of electric power to get worse. Research on the simulation method uses a single filter as a filter that is adjusted to reduce distortion caused by non-linear loads using personal computers and printers for printing machines. Where the measurement uses a Fluke Power quality analyzer, the resulting non-linear load value is obtained on non-linear loads with personal computer loads brand A has a THDi of 120.7\% decreasing to $110.8 \%$, brand B THDi of $121.9 \%$ becomes $109.9 \%$, the C THDi brand by $150.1 \%$ decreased to $100.2 \%$, the D THDi brand by $176.2 \%$ decreased to $104.1 \%$ where the decrease in the total harmonic current distortion after reduction was $0.8-1 \%$. The use of a filter was successful in lowering the THDi value.
\end{abstract}

Keywords: THD, distortion analyzer, power quality, harmonics.

\section{Pendahuluan}

Harmonisa merupakan pengoperasian listrik dari beban tidak linier sehingga terbentuklah gelombang frekuensi tinggi yang merupakan kelipatan dari frekwensi dasar $50 \mathrm{~Hz}$ atau $60 \mathrm{~Hz}$, sehingga bentuk gelombang arus maupun tegangan yang idealnya adalah sinusoidal murni akan

TELKA, Vol.7, No.1, Mei 2021, pp. 71 76

ISSN (e): 2540-9123

ISSN (p): 2502-1982 
menjadi cacat. Harmonisa berdasarkan dari urutan ordenya adalah harmonisa ke 3, 5, 7, 9, 11, dan seterusnya seperti yang terlihat pada Gambar 1[1-4]. Semakin banyaknya penggunaan beban tidak linier diperkirakan harmonisa yang ditimbulkan akan semakin besar dan dapat mengganggu sistem kinerja dari peralatan elektronika lainnya dan juga dapat menyebabkan panas berlebih pada sumber tenaga listrik dalam peralatan kerja[5-7]. Penggunaan Personal Computer (PC) merupakan salah contoh yang menimbulkan permasalahan terhadap pengaruhnya qualitas sistem tenaga. Komputer merupakan salah satu beban tidak linier yang menghasilkan harmonisa[4]. Dari hasil pengukuran PC dual core menggunakan monitor 15 inci dan mesin cetak printer menunjukan adanya harmonisa yang harus disesuaikan dengan standart IEC 61000-3-2 kelas D [2],[4].

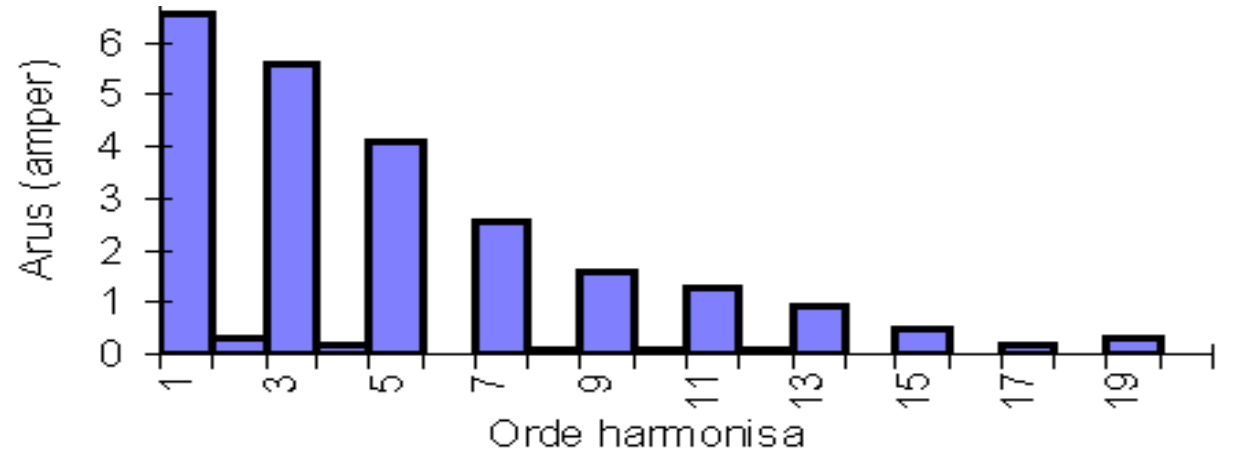

Gambar 1. Urutan orde harmonisa.

Komputer adalah alat elektronik yang mempunyai komponen utama dengan bagian central prosessing unit (CPU), dan komponen hardware seperti monitor, keyboard, mouse dan speaker. Komputer merupakan sistem elektronik untuk mengolah data dengan cepat dan tepat serta akurat yang telah dirancang dan diorganisasikan dapat secara otomatis menerima dan menyimpan data input atau masukan, kemudian memprosesnya dan menghasilkan output dibawah pengawasan suatu langkah dan instruksi program yang tersimpan di memori. Kandungan harmonisa yang dihasilkan oleh beban tidak linier personal computer (PC) dengan monitor LCD 15 inci dan mesin cetak printer, memiliki besar nilai IHDi, dan THDi [3-5],[8-9].

Penelitian ini mensimulasikan penggunaan filter pasif single tuned pada 4 merk PC yang berbeda untuk mereduksi arus individual harmonic distorsi (IHDi) pada beban non linier tersebut. PC merk A memiliki THDi sebesar 120,7 \% dan THDv sebesar 2,0\%, PC merk B memiliki THDi sebesar 121,9\% dan THDv sebesar 2,2\%, PC merk C memiliki THDi sebesar 150,1\% dan THDv sebesar 2,0\%, PC merk D memiliki THDi sebesar 176,2\% dan THDv sebesar 2,3\%. Berdasarkan data tersebut maka perlu dilakukan pengurangan kandungan harmonisa dengan pemasangan filter yang diharapkan dapat mengurangi harmonisa yang disebabkan oleh PC.

\section{Metode Penelitian}

\subsection{Perancangan penelitian}

Metode yang dilakukan pada penelitian ini adalah pengukuran langsung beban tidak linier dengan parameter pengukuran berupa arus individual harmonic distorsion (IHDi), total harmonic distortion arus (THDi), individual harmonic distorsi tegangan (IHDv), total harmonic distorsi tegangan (THDv), daya aktif, daya reaktif, dan faktor daya, yang dihasilkan oleh beban non linier personal computer (PC), monitor, dan penambahan mesin cetak printer pada saat beroperasi. Untuk mengetahui besar nilai harmonisa yang dihasilkan oleh objek penelitian dilakukan dengan pengukuran menggunakan alat ukur power quality analyzer fluke.

Beban lengkap pengukuran tidak linier yang dipakai pada penelitian ini adalah PC dual core menggunakan monitor liquid crystal diode (LCD) 15 inci dan satu buah mesin cetak printer berjumlah empat buah dengan merk berbeda, kemudian diukur secara bergantian dan diberi nama sebagai PC merk A, B, C, dan D. Pengukuran dilakukan dengan menggunakan power quality 
analyzer fluke. Skema pengukuran dapat dilihat pada Gambar 2, dengan melakukan pengukuran di sisi jaringan phasa. Dari pengukuran tersebut akan diambil nilai dari parameter total distorsi harmonisa arus (THDi) dan total distorsi harmonisa tegangan (THDv) yang tertinggi untuk kemudian dibandingkan dengan standart IEC 61000-3-2 kelas D.

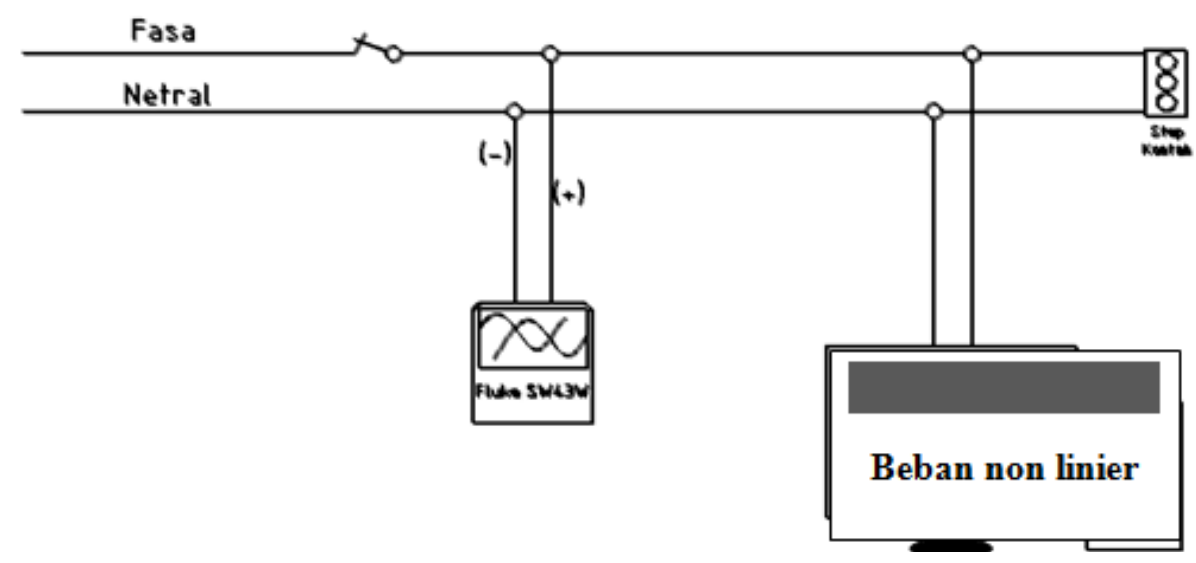

Gambar 2. Rangkaian pengukuran.

Pengukuran yang dilakukan pada beban non linier menghasilkan data harmonik seperti terlihat pada Gambar 3. Arus yang tidak standar dari hasil pengukuran didapat dari gelombang terdistorsi pada arus yang berbentuk tidak sinusoidal. Dari data pengukuran masih terdapat harmonisa tegangan pada berbagai PC tersebut yang tidak memiliki standart IEC 61000-3-2 kelas D yang dapat mempengaruhi gelombang pada arus dan tegangan pada bilangan ganjil yang menghasilkan bentuk non sinusoidal dengan cacat gelombang.

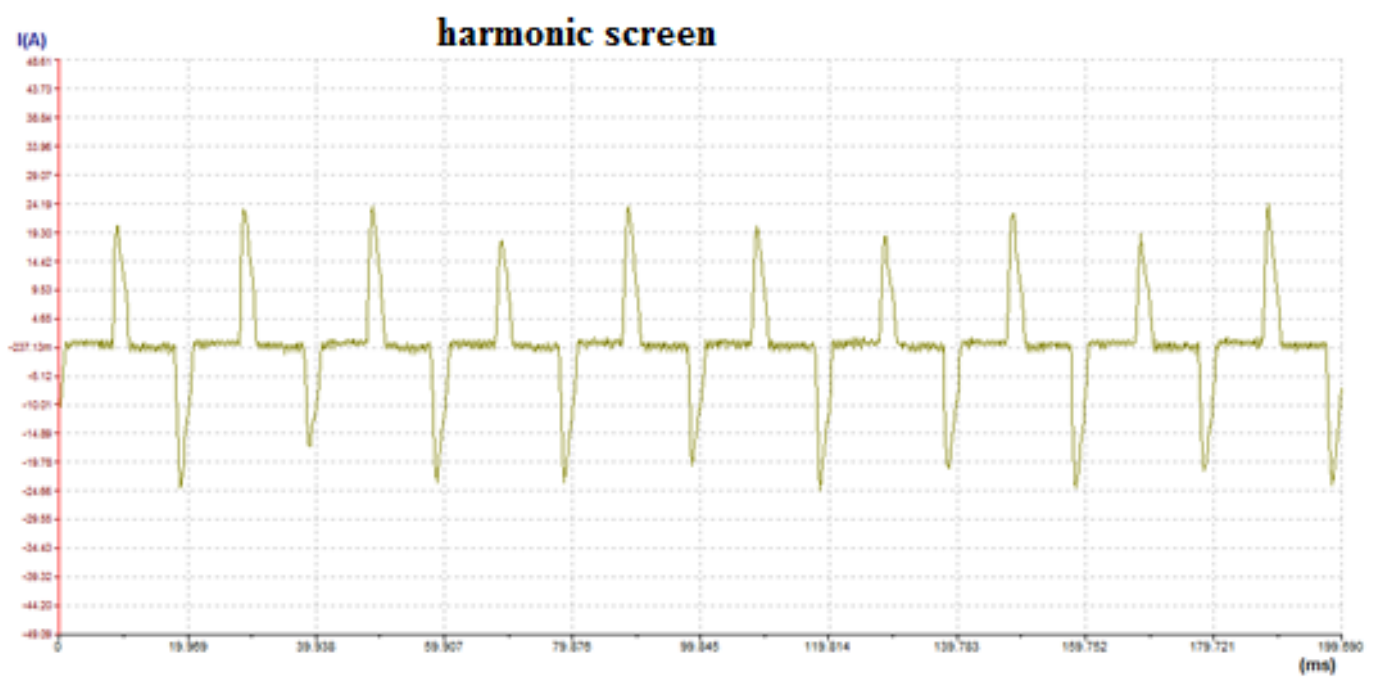

Gambar 3. Gelombang arus.

Bentuk spektrum hasil pengukuran, khususnya gelombang arus, didapat bentuk dari spektrum arus pada beban PC yang tidak sinusoidal dan terdistorsi. Harmonisa arus yang paling tinggi yaitu pada harmonisa bilangan ganjil pada bilangan ke-tiga, ke-lima dan seterusnya yang merupakan gelombang yang cacat. Bebean non linier menghasilkan gelombang harmonisa puncak tinggi. Hal ini dapat dilihat dari pengukuran yang menunjukkan bahwa harmonisa berbentuk gelombang tidak sinusoidal dan membentuk gelombang arus pendek. Arus harmonisa yang dihasilkan oleh beban tidak linier disuntikkan kembali ke saluran sumber daya listrik, 
berputar secara berkala terus-menerus dengan skala waktu yang mendekati nilai puncak yang tidak terbaca dengan simulasi. Bentuk spektrum tersebut menggambarkan terjadinya distorsi pada beban.

\section{Hasil dan Pembahasan}

\subsection{Simulasi THDi}

Simulasi rangkaian pengukuran untuk mereduksi harmonisa dilakukan dengan menggunakan filter untuk dapat menurunkan nilai harmonisa sehingga sesuai dengan standrat IEC 61000-3-2 kelas D seperti yang terlihat pada Gambar 4. Pada Gambar 5 terlihat gelombang arus yang memiliki harmonisa sebelum dilakukaan filter.

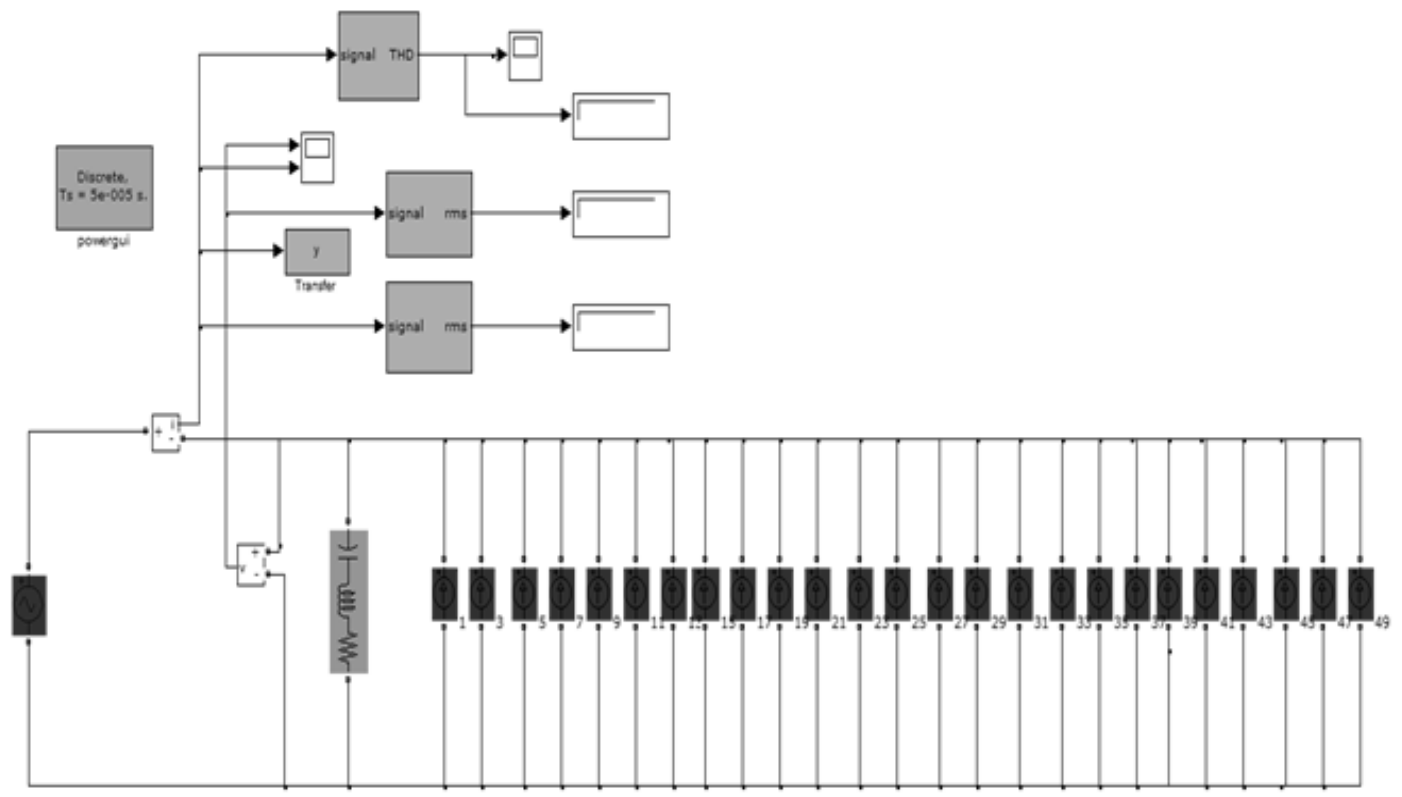

Gambar 4. Simulasi Rangkaian Reduksi.

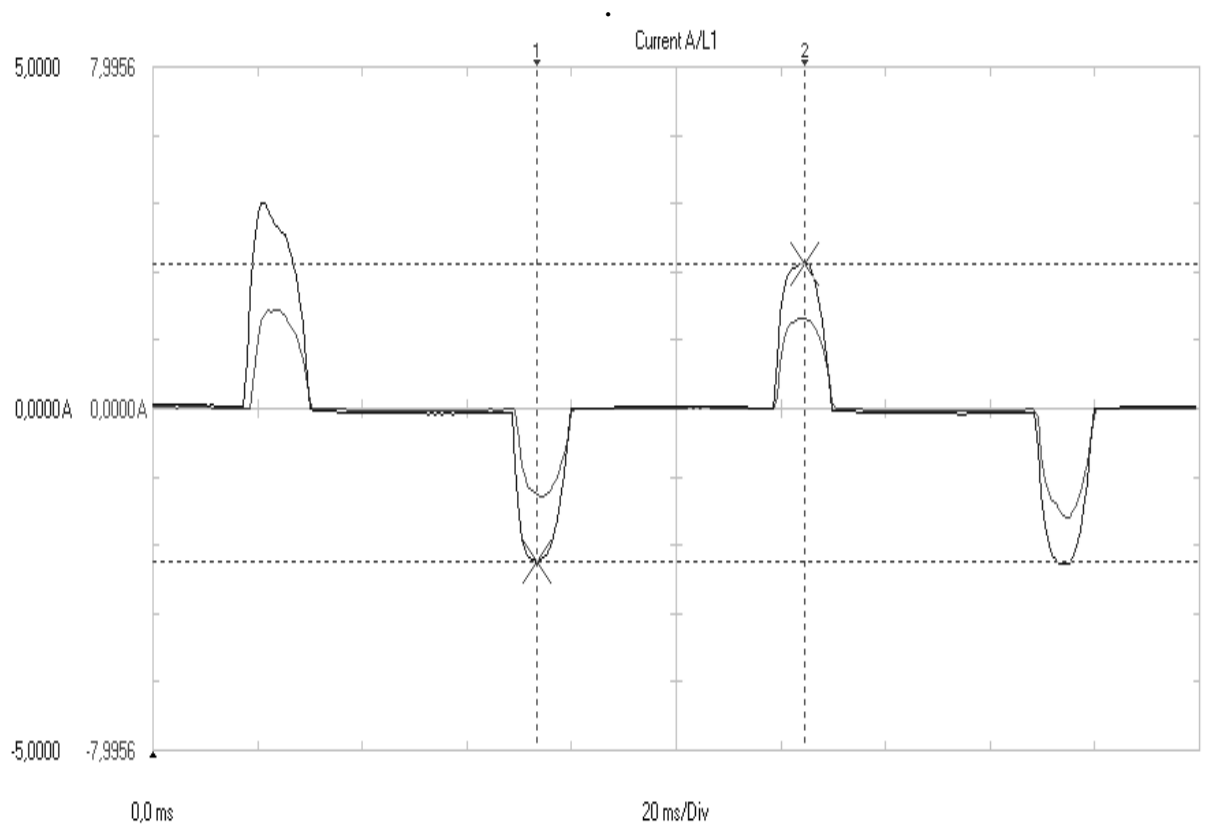

Gambar 5. Gelombang arus setelah direduksi. 


\subsection{Tabel Data Reduksi}

Dari hasil pengukuran dan dilakukan reduksi terhadap ordo arus harmonisa yang memiliki nilai yang tidak standrat IEC 61000-3-2 kelas D. Nilai dari arus harmonik pada beban menurun, dimana total harmonic distorsion yang didapat terhadap beban menurun hingga $0,8-1 \%$ dari pengukuran awal sebelum filter seperti terlihat pada Tabel 1.

Tabel 1. Reduksi IHDi.

\begin{tabular}{ccccc}
\hline \multirow{2}{*}{ Harmonisa } & \multicolumn{4}{c}{ Nilai Reduksi IHDi (Ampere) } \\
\cline { 2 - 4 } & A & B & C & 0,541 \\
3 & 0,280 & 0,128 & 0,453 & 0,469 \\
5 & 0,253 & 0,119 & 0,398 & 0,360 \\
7 & 0,299 & 0,113 & 0,294 & 0,226 \\
9 & 0,181 & 0,097 & 0,179 & 0,103 \\
11 & 0,140 & 0,084 & 0,074 & 0,031 \\
13 & 0,093 & 0,067 & 0,038 & 0,063 \\
15 & 0,053 & 0,051 & 0,075 & 0,075 \\
17 & 0,020 & 0,035 & 0,087 & 0,060 \\
19 & 0,012 & 0,021 & 0,072 & 0,032 \\
21 & 0,022 & 0,010 & 0,046 & 0,017 \\
23 & 0,024 & 0,002 & 0,022 & 0,025 \\
25 & 0,021 & 0,004 & 0,019 & 0,027 \\
27 & 0,014 & 0,008 & 0,023 & 0,020 \\
29 & 0,005 & 0,009 & 0,019 & 0,010 \\
\hline THDi $\%)$ & 0,005 & 0,008 & 0,010 & 104,1 \\
\hline
\end{tabular}

Grafik arus setelah direduksi dapat dilihat pada Gambar 6. Pada setiap ordo negatif memiliki penurunan nilai harmonik. Penurunan nilai total harmonik dapat dilihat pada Gambar 7 dengan nilai penurunan sebesar 0,8 - 1 persen dari nilai sebelum direduksi.

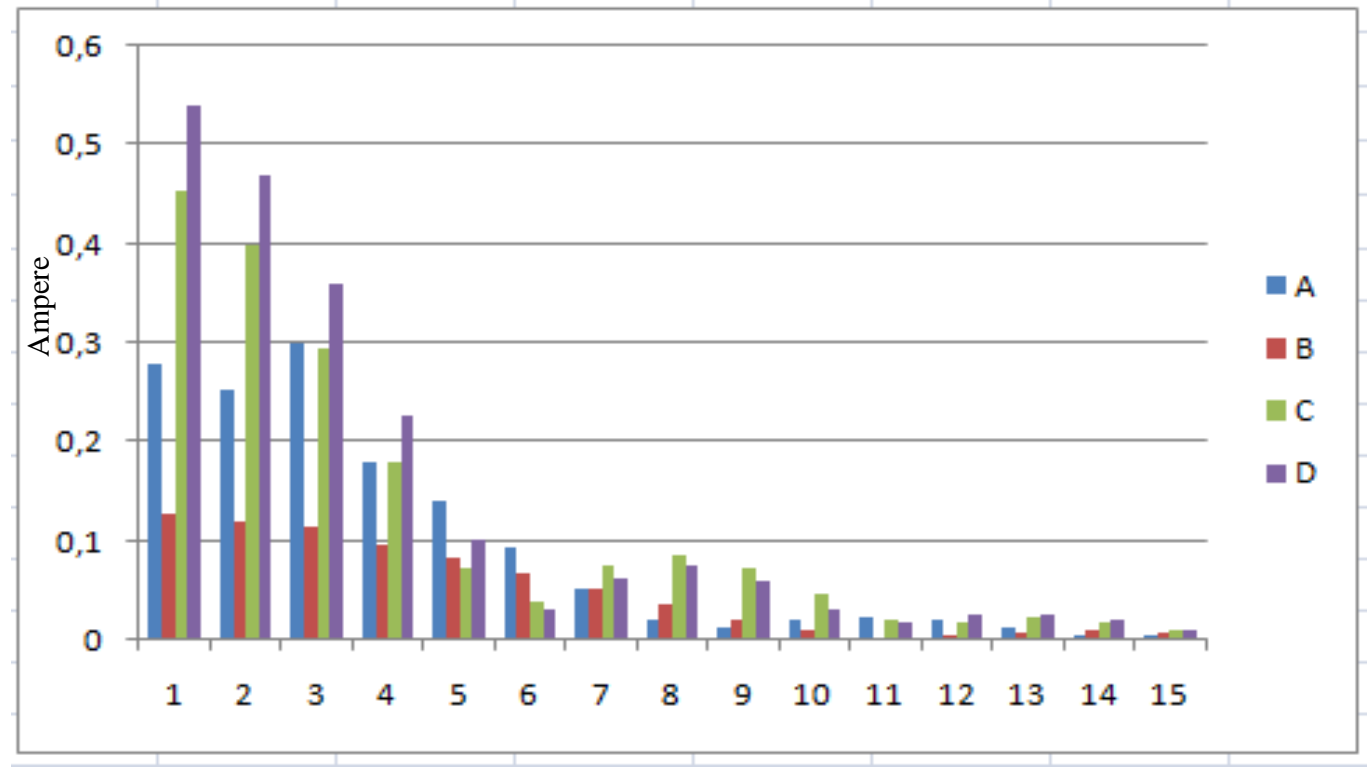

Gambar 6. Grafik arus setelah direduksi. 


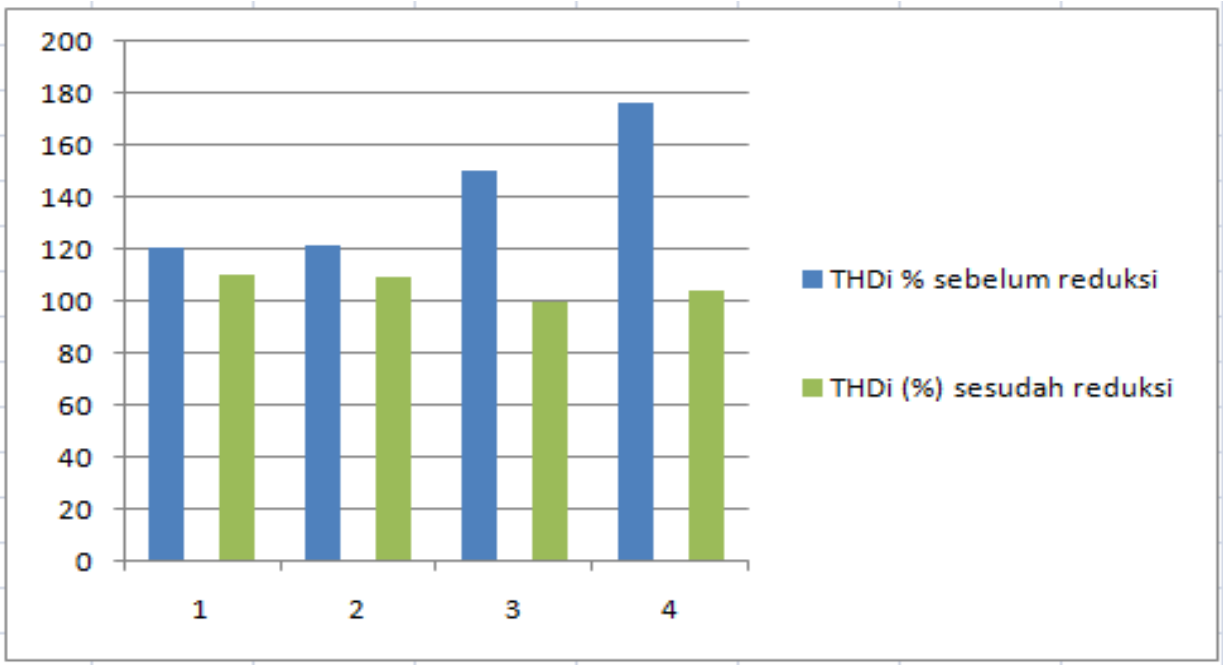

Gambar 7. Grafik THDi \% sebelum dan sesudah direduksi.

\section{Kesimpulan}

Kesimpulan nilai beban non linier yang dihasilkan pada beban non linier berupa PC mengalami penurunan. Penurunan tersebut bervariasi untuk setiap merk PC. Merk A dari THDi sebesar 120,7 \% menurun menjadi 110,8\%, merk B dari THDi sebesar 121,9\% menjadi 109,9\%, merk C dari THDi sebesar 150,1\% menurun menjadi 100,2 \%, dan merk D dari THDi sebesar $176,2 \%$ menurun menjadi $104,1 \%$. Penurunan total harmonik distorsi arus setelah direduksi sebesar $0,8-1 \%$. Filter yang disimulasikan berhasil menurunkan nilai THDi pada beban non linier.

\section{Referensi}

[1] Peter Norton. Introduction to computer. Edisi delapan The Mc Graw hill compenies, 2008.

[2] Chang-Song Li, Zhi-Xuan Bai, Xian-Yong Xiao, Ya-Mei Liu and Yi Zhang, "Research of harmonic distortion power for harmonic source detection," 17th International Conference on Harmonics and Quality of Power (ICHQP), pp. 126-129, 2016

[3] Srđan Đorđević, Marko Dimitrijević, Vančo Litovski, "A Non-Intrusive Identification Of Home Appliances Using Active Power And Harmonic Current," Facta Universitatisseries: Electronics and Energetics, vol. 30, no. 2, pp. 199-208, June 2017

[4] M. Fadlan S., Jhoni Hidayat., Syamsul Bahri, "Perbandingan Nilai Distorsi Harmonisa pada Tiga Buah Laptop yang Berbeda" Journal of Electrical Technology, Vol. 3, No. 2, Juni 2018.

[5] Arrilaga, Jos and Watson Neville. Power system Harmonic. Second Edition John Wiley \& Sons, Ltd ISBN: 0-470-85129-5, 2003.

[6] X. Wang, F. Blaabjerg and W. Wu, "Modeling and Analysis of Harmonic Stability in an AC Power-Electronics-Based Power System," IEEE Transactions on Power Electronics, vol. 29, no. 12, pp. 6421-6432, Dec. 2014

[7] Young Sik Cho, Hanju Cha, "Single tuned passive harmonioc filter design considering variances of tuning and quality factor," Jurnal Of International Countil On Electrical Engineering, $1: 7-13,2011$.

[8] Syafriwel, "Analisis Ramalan Kebutuhan Beban Energi Listrik di Regional Sumatera Utara Tahun 2015-2019 dengan Metode Gabungan," Jurnal Teknovasi: Jurnal Teknik dan Inovasi, vol. 2, no. 2, 2015

[9] MF Siregar, "Sistem Pemutus Tiga Fasa Berdasarkan Pendeteksian Secara Otomatis," JET (Journal of Electrical Technology), vol. 3, no. 1, 2018 